\title{
Health Professional Assisted Kangaroo Mother Care Practice in Ethiopian Health Facilities: Evidence from the 2016 Ethiopian Demographic and Health Survey Data
}

\author{
Mesfin Wudu Kassaw ( $\nabla$ mesfine12a@gmail.com ) \\ Woldia University \\ Ayele Mamo Abebe \\ Debre Berhan University \\ Biruk Beletew Abate \\ Woldia University \\ Ayelign Mengesha Kassie \\ Woldia University \\ Kirubel Dagnaw Tegegne \\ Wollo University
}

\section{Research}

Keywords: Children, Associations, KMC, Health professional, Health facilities

Posted Date: August 26th, 2020

DOI: https://doi.org/10.21203/rs.3.rs-61512/v1

License: (c) (1) This work is licensed under a Creative Commons Attribution 4.0 International License.

Read Full License 


\section{Abstract}

Background Worldwide, 15 million babies born prematurely every year and over one million babies died because of premature birth complications. However, three-fourths of deaths from preterm birth complications are preventable without intensive care units. One of the prevention methods is Kangaroo Mother Care, which is a method of holding a small neonate in skin-to skin contact, upright prone position on the maternal chest. An evidence stated that KMC can prevent up to half of all deaths in babies weighing $<2000 \mathrm{gm}$ at birth. Ethiopian guidelines also mentioned that all LBW babies need to receive KMC. The aim of this study was to assess health professional assisted Kangaroo mother care practice and association among mothers who gave birth in a health facility in Ethiopia.

Methods This study produced from the 2016 Ethiopian Demographic and Health Survey data (EDHS). The 2016 EDHS used a stratified two stage sampling method to select a representative sample for the country, Ethiopia. According to the 2016 EDHS data, all the regions were stratified into urban and rural areas. The study sample refined from EDHS and used in this secondary analysis is 2,760 mother-child pairs. A logistic regression model was used to assess the associations with the size of a child at birth.

Results mothers who gave birth in a health facility and practiced kangaroo mother care were 1808 (62.1\%), 95\% Cl $(60,3,63.9)$. The others $1102(37.9 \%), 95 \% \mathrm{Cl}(36.1,39.7)$ of mothers did not practiced KMC, although they were gave birth in health facilities under the support of trained health professionals. In the multivariable logistic regression analysis, only wealth index, poorest ((AOR), $(95 \% \mathrm{Cl})),((0.60),(0.43$, $0.81))$, and poorer $((0.62),(0.46,0.86))$ were associated with health professionals assisted KMC practice.

Conclusions The prevalence of health professional assisted KMC practice was low, which was far lower than the expectation for mothers who gave birth in health facilities. Low socio-economic status was protective for not practicing KMC. The reason might be that mothers from higher income households might not initiate breast feeding, which might contribute for not practicing KMC. Thus, the minister of health or other researchers should study further why mothers from high income did not practicing KMC in considering the assumption of this author.

\section{Plain English Summary}

Three-fourths of neonatal deaths from preterm birth complications are preventable without intensive care units. One of the prevention methods is Kangaroo Mother Care, which is a method of holding a small neonate in skin-to skin contact, upright prone position on the maternal chest.

The Ethiopian guidelines mentioned that all low birth weight babies need to receive kangaroo mother care. The aim of this study was to assess health professional assisted Kangaroo mother care practice and associations among mothers who gave birth in a health facility in Ethiopia.

This study produced from the 2016 Ethiopian Demographic and Health Survey data (EDHS). The 2016 EDHS used a stratified two stage sampling method to select a representative sample for the country, 
Ethiopia. According to the 2016 EDHS data, all the regions were stratified into urban and rural areas. The study samples used in this secondary analysis is 2,760 mother-child pairs.

A logistic regression model was used to assess the associations with the size of a child at birth.

The total numbers of mothers who gave birth in a health facility and practiced kangaroo mother care were $1808(62.1 \%)$. In the multivariable logistic regression analysis, only wealth index, poorest ((AOR), $(95 \% \mathrm{Cl})),((0.60),(0.43,0.81))$, and poorer $((0.62),(0.46,0.86))$ associated with health professionals assisted KMC practice. Hence, the prevalence of health professional assisted KMC practice was low.

\section{Article Summary}

\section{Strengths}

- This is the first study that assessed the impact of health professionals on increasing KMC practice in health facilities

\section{Limitations}

- It consider only mothers who were under the follow up of a professional and might decrease the prevalence of KMC

- Through exhaustive screening or selecting case, the sample size become too small

\section{Background}

Worldwide, 15 million babies born prematurely every year and over one million died because of premature birth complications (1). Preterm birth (birth before 37 completed weeks of gestation) is the direct and leading cause to three million neonatal deaths each year and the second leading cause of all deaths in under-five children globally $(2,3)$. However, three-fourths of deaths from preterm birth complications are preventable without intensive care units (4). Neonatal period by itself presents the greatest risk of death, which is exacerbated for preterm newborns as they have less physiological reserve, have greater challenges in temperature regulation, have immature organs, have poor immune function, and heightened vulnerability to severe infections putting them at risk for problems associated with the transition to extra uterine life $(5,6)$. Because of these and many other reasons, neonatal health begun to emerge as a global and national public health priority, especially through attention to child survival in the Millennium Development Goals(7), which contribute more to emphasize on Kangaroo Mother Care (KMC). Kangaroo Mother Care is a method of holding a small neonate $(<2000 \mathrm{gm})$ in skin-to skin contact (STS), prone and upright on the maternal chest. The neonate is enclosed in maternal clothing for thermal regulation (8). $\mathrm{KMC}$ is an evidence-based inpatient care technique for premature and low-birth weight (LBW) baby when he/she weigh less than $2000 \mathrm{gm}(9,10)$. It is an easily available and biologically sound method of care for all newborns, but in particular for premature babies (11). The clinical efficacy and health benefits of $\mathrm{KMC}$ to preterm and low-birth weight babies (<2000 gm) has been widely demonstrated. According to a 
study, KMC can prevent up to half of all deaths in babies weighing $<2000 \mathrm{gm}$ at birth (10). According to Ethiopian and World Health Organization (WHO) guidelines, all LBW babies need to receive KMC. But, sick and very small neonates should initially be cared in a radiant warmer and KMC would be initiated once the baby is thermodynamically stable (12). However, KMC may use in economically challenged countries like Ethiopia where access to conventional services of incubators is limited or too expensive for the general population (13). KMC is a strategy to decrease neonatal mortality in Ethiopia as stated in the HSTP, but only $46.4 \%$ of eligible babies were received KMC (14). This indicated that the coverage of KMC has remained low and its implementation has largely been limited to specialized hospitals $(15,16)$. However, KMC shorten hospital stay and create opportunities for teaching mothers and assessing the progress, and means for better use of health care (10,17-19). Furthermore, a study indicated a difference in between health facilities on practicing KMC in the country, Ethiopia (20). Unlike Ethiopia, KMC has been widely implemented in western and some African countries including Nigeria, Madagascar, Malawi, Ghana, Indonesia $(21,22)$ and South Africa $(23)$. Thus, the aim of this study was to assess health professional assisted Kangaroo mother care practice and association among mothers who gave birth in health facilities in Ethiopia.

\section{Methods}

\section{Data collection period, study design, and data collection procedure}

The data collection period for the 2016 EDHS was from January 18 to June 27, 2016. The 2016 Ethiopian Demographic and Health Survey (EDHS) data was used for this further analysis. The 2016 EDHS data was the fourth survey conducted in Ethiopia. The survey collected information on household's and respondent's characteristics, child health, infant and child mortality, malaria, maternal health, maternal mortality, nutrition, tobacco use, women's empowerment, anemia, domestic violence, environmental health, family planning, female genital cutting, fertility and fertility preferences, and etc. The purpose of the EDHS is to provide up-to-date estimates of the key demographic and health indicators of the population (24). The survey included reproductive age group women, under-five children, and productive age group men (aged $15-59$ years) $(24,25)$

\section{Sampling technique and study population}

The 2016 EDHS data was collected using a stratified two stage sampling method to select a representative sample. All the regions of the country were stratified into urban and rural areas. From all the 11 administrative states, 21 sampling strata were yielded. The samples of enumeration areas (EAs) were selected independently in each stratum at two stages. The implicit stratification and proportional allocation were achieved at each of the lower administrative levels by sorting the sampling frame within each sampling stratum before sample selection according to the administrative units in the different levels, and by using a probability proportion to size selection at the first stage of sampling. For the 2016 
EDHS data collection, 645 EAs were selected with a probability proportional to the EA size and with independent selection in each sampling stratum. The EA size is the number of residential households in the EA that was determined in the 2007 Ethiopian Population and Housing Census. According to the 2016 EDHS procedures, a household listing operation was implemented in the selected EAs, and the resulting lists of households served as the sampling frame for the selection of households in the second stage. The data collectors interviewed only the pre-selected households. In the EDHS, there were no replacements or changes of the pre-selected households in the implementing stages to prevent bias. All the under-five children, who were usual members of the selected households or who spent the night before the survey in the selected households were eligible for the child survey (25). After managing the missing data, 2910 respondents that had under-five children were included for this further analysis. However, the 2016 EDHS data collected data from 10641 children.

\section{Data collection tools and procedures}

The 2016 EDHS usually use five groups of questionnaires in collecting the data. Those questionnaires are the Household questionnaire, the woman's questionnaire, the man's questionnaire, the biomarker questionnaire, and the health facility questionnaire. The questionnaires were adapted from the DHS program's standard demographic and health survey questionnaires in a way to reflect the population and health issues relevant to Ethiopia. Questions that stated about children were integrated to woman's questionnaire.

Variables The outcome variable of this further analysis was health professional assisted KMC. The independent variable were socio-demographic variables of both children and mothers, health services provided to children and the wider community, and substance use like cigarette smoking and Khat chewing in considering the availability of the variables in the 2016 EDHS data.

\section{Definition}

KMC: Holding a small neonate ( $<2000 \mathrm{gm}$ ) in the mothers' skin in a prone and upright position on the maternal chest that also enclosed in maternal clothing for thermal regulation (8).

Health professional assisted KMC: Practice of KMC under the HCPs initiation for mothers who gave birth in health facilities.

Data analysis: The data analysis started with a summary of socio-demographic characteristics, and other relevant factors of the respondents. A logistic regression model was used to assess the association of health professionals assisted KMC. A statistically significant association was determined at a p-value of less than 0.05 .

\section{Results}




\section{Socio-demographic characteristics study subjects}

In this study, 1040(35.7\%) husbands were had agricultural jobs, but 1658(57.0\%) mothers had no professional jobs. More than fifty seven percent $1667(57.3 \%)$ of mothers were rural residents, 2867(98.5\%) mothers were married, and 1036(35.6\%) mothers were completed primary education. Regarding religion $1224(42.1 \%)$ mothers were Orthodox, and 1139(39.1\%) mother were unable to read and write.

\section{Health professional assisted KMC}

The prevalence of health professional assisted KMC practice among mothers who gave birth in a health facilities were 1808 (62.1\%), 95\% Cl $(60,3,63.9)$. The others $1102(37.9 \%), 95 \% \mathrm{Cl}(36.1,39.7)$ of mothers did not practiced $\mathrm{KMC}$, although they were gave birth in a health facilities under the support of trained health professionals.

\section{Associations of health professionals assisted KMC}

On binary logistic regression analysis, wealth index, region, cigarette smoking, religion, maternal education and child size were associated with health professional assisted KMC practice. In the final model, only wealth index, poorest ((AOR), $(95 \% \mathrm{Cl})),((0.60),(0.43,0.81))$, and poorer $((0.62),(0.46,0.86))$ were associated with health professionals assisted KMC.

\section{Discussions}

The aim of this study was to assess the practice and association of Kangaroo mother care among mothers who gave birth at health facilities in Ethiopia. The practice of $\mathrm{KMC}$ among mothers who gave birth in the health facilities was 1808 (62.1\%), 95\% Cl (60,3, 63.9). The others $1102(37.9 \%), 95 \% \mathrm{Cl}(36.1$, 39.7) of mothers did not practiced KMC while they were in health facilities, although they gave birth in a health facilities too. The current study's level of KMC practice is higher than studies that reported $41.9 \%$ $\mathrm{KMC}$ (26), 46.4\% KMC, 54.15\% KMC (27), and 28.1\% KMC (28). The difference might be as a result of study population difference, sample size difference, eligibility criteria, and socio-demographic difference. Our study considered only mothers who followed by health professionals starting from before birth, during birth, and till post-partum. However, all the referred papers included mothers who visited health facilities in post-partum irrespective of their place of birth. The present study reported a lower KMC practice than a study reported from Ghana that was $84.6 \%$ (29). This variation might be because of sociodemographic difference between Ghana and Ethiopia. In addition, the health care service provided in Ghana might be better than in Ethiopia. Furthermore Ethiopia integrated KMC to the National Strategy for Newborn and Child Survival lately in 2015/16 than Ghana that started some years before Ethiopia (30). The current study have a similar KMC practice with a study that conducted from Ghana, home based KMC practice (29), and other study that reported $61.6 \%$ (31). This also reflects the socio-demographic 
difference between the study areas, Ethiopia and Ghana. Because the KMC practice in the Ethiopian health facilities become equal with Ghanaian Home based KMC practice. In assessing the association of $\mathrm{KMC}$ and determinates, religion, residence, wealth index, maternal education, and birth weight were associated with health professional assisted KMC practice at binary logistic regression model. However, in the final model, logistic regression, only wealth index was associated with health professional assisted KMC practice. Mothers who had poorest ((AOR), $(95 \% \mathrm{Cl}),((0.60),(0.43,0.81)$ and poorer $((\mathrm{AOR}),(95 \% \mathrm{Cl})$, $((0.62),(0.46,0.86)$ wealth index were more prone to practice $\mathrm{KMC}$ than mothers from richest households. However, a study from Aksum, Ethiopia reported the lack of association between neonatal care, KMC practice and wealth index (32). The difference in these studies might be as a result of study area variation. Our study derived from EDHS, in which both urban and rural areas represented proportionally. However, the study from Aksum considers only urban residents, who might have similar degree of economic class. This positive as

\section{Conclusions}

The prevalence of health professional assisted KMC practice was low, which was far lower than the expectation for mothers who gave birth in health facilities. The lowest wealth index was protective for not practicing KMC. The reason might be that mothers from higher income households might not initiate breast feeding, which might contribute for not practicing KMC. Thus, the minister of health or other researchers should study further why mothers from high income did not practicing $\mathrm{KMC}$ in considering the assumption of this author.

\section{Limitations}

Some of the variables were excluded while managing the missing values. Due to this, the sample size was small that might compromise the inclusiveness of this research.

\section{Abbreviations}

AOR - adjusted odds ratio; $\mathrm{Cl}$ - confidence interval; SPSS - statistical package for social science; WHO World Health Organization; EDHS - Ethiopian demography and health survey, DHS - Demography and health survey; SNNPR - Southern nation nationalities and people representatives; EA - Enumeration areas; USAID- The United states Agency for International Development, and ICF- Inner City Fund, KMC-Kangaroo Mother Care; LBW- low-birth weight; NMR-newborn mortality.

\section{Declarations}

\section{Ethics approval and consent to participate}

Not applicable

\section{Consent for publication}


Not applicable

\section{Availability of data and materials}

The raw materials that support the conclusions of this research can be uploaded as a supplementary file together with the manuscript documents.

\section{Competing interests}

The authors have no conflict of interests

\section{Funding}

Not applicable

\section{Author's contribution}

For this study MWK, SAM, AMA, AMK, and BBA Conceived the title and designed the study, preparing a complex data for analysis, analyzing the complex data, critically revising the work and writing the final manuscript. All the authors read and approved the final version of this manuscript. The authors agreed to be accountable for all aspects of this work.

\section{Acknowledgments}

We would like to acknowledge the central statistical agency of Ethiopia staff, and DHS database librarian for their willingness and effort to provide the data online in collaboration with the USAID

\section{References}

1. Bhutta ZA, Das JK, Bahl R, Lawn JE, Salam RA, Paul VK, et al. Can available interventions end preventable deaths in mothers, newborn babies, and stillbirths, and at what cost? The Lancet, 2014; 384(9940):347-70.

2. Liu L, Johnson HL, Cousens S, Perin J, Scott S, Lawn JE, et al. Global, regional, and national causes of child mortality: an updated systematic analysis for 2010 with time trends since 2000 . The Lancet, 2012; 379(9832):2151-61.

3. UNICEF. Levels and trends in child mortality report 2012: estimates developed by the UN interagency group for child mortality estimation. New York: UNICEF, the World Health Organization, the World Bank, and the United Nations Population Division; 2012.

4. Organization WH. Born too soon: the global action report on preterm birth. 2012

5. Lunze K, Hamer D. Thermal protection of the newborn in resource-limited environments. Journal of Perinatology. 2012; 32(5):317-24.

6. Howson C, Kinney M, Lawn J. March of Dimes, PMNCH, Save the children, WHO. Born too soon: the global action report on preterm birth Geneva: World Health Organization. 2012 
7. Requejo JH, Bryce J, Barros AJ, Berman P, Bhutta Z, Chopra M, et al. Countdown to 2015 and beyond: fulfilling the health agenda for women and children. The Lancet, 2015; 385(9966):466-76.

8. Charpak N, Gabriel Ruiz J, Zupan J, Cattaneo A, Figueroa Z, Tessier R, et al. Kangaroo mother care: 25 years after. Acta Paediatrica. 2005; 94(5):514-22.

9. WHO. WHO recommendations on interventions to improve preterm birth outcomes. 2015

10. Lawn JE, Mwansa-Kambafwile J, Horta BL, Barros FC, Cousens S. 'Kangaroo mother care to prevent neonatal deaths due to preterm birth complications. International journal of epidemiology, 2010;39(suppl_1):i144-i54.

11. Heidarzadeh M, Hosseini MB, Ershadmanesh M, Tabari MG, Khazaee S. The effect of kangaroo mother care (KMC) on breast feeding at the time of NICU discharge. Iranian Red Crescent Medical Journal. 2013; 15(4):302.

12. Chan GJ, Labar AS, Wall S, Atun R. Kangaroo mother care: a systematic review of barriers and enablers. Bulletin of the World Health Organization; 2016;94(2):130.

13. Butler AS, Behrman RE. Preterm birth: causes, consequences, and prevention: National academies press; 2007.

14. University M. KMC Implementation Research for Accelerating Scale-up: Generic Protocol; Version 4.0.

15. World Health Organization. Every newborn: an action plan to end preventable deaths. 2014

16. Vesel L, Bergh A-M, Kerber KJ, Valsangkar B, Mazia G, Moxon SG, et al. Kangaroo mother care: a multi-country analysis of health system bottlenecks and potential solutions. BMC pregnancy and child birth. 2015; 15(S2):S5.

17. Charpak N, Ruiz-Peláez JG, Charpak Y. A randomized, controlled trial of kangaroo mother care: results of follow-up at 1 year of corrected age. Pediatrics. 2001; 108(5):1072-9.

18. Affonso D. Exploration of mothers to the kangaroo method of prematurity care. Neonatal-Netw. 1989:43-51.

19. Charpak N, Ruiz-Peláez JG, Zita Figueroa de C M, Charpak Y. Kangaroo mother versus traditional care for newborn infants $\leq 2000$ grams: a randomized, controlled trial. Pediatrics. 1997; 100(4):682-8.

20. Weldearegay HG, Medhanyie AA, Abrha MW, Tadesse L, Tekle E, Yakob B, et al. Quality of Kangaroo Mother Care services in Ethiopia: Implications for policy and practice. PloS one. 2019;14(11).

21. Bergh Am, Arsalo I, MAIAN AF, Patrick M, Pattinson RC, Phillips N. Measuring implementation progress in kangaroo mother care. Acta Paediatrica. 2005; 94(8):1102-8.

22. Ten Ham W, Minnie KC, Van der Walt CS. Health care professionals' perspectives on the requirements facilitating the roll-out of kangaroo mother care in South Africa. health sagesondheid. 2016; 21(1):228-37.

23. Bergh A-M, Van Rooyen E, Pattinson RC. Scaling up kangaroo mother care in South Africa: on site versus' off-site' educational facilitation. Human resources for health. 2008; 6(1):13.

24. YD. W. Women's autonomy and reproductive health-care-seeking behavior in Ethiopia. Women \& health. 2017:1-15. 
25. G. P. Do conditional cash transfers improve child health? Evidence from PROGRESA's control randomized experiment. Am Econ Rev. 2004;94(33641):22.

26. Yusuf E, Fiseha F, Dulla D. Utilization of Kangaroo Mother Care (KMC) and Influencing Factors among Mothers and Care Takers of Preterm/Low Birth Weight Babies in Yirgalem Town, Southern, Ethiopia. 2018

27. Roba A, Binoy S, Naganuri M. Knowledge, Attitude and Practice of Kangaroo Mother Care by Postnatal Mothers who Gave Birth to Preterm and Low Birth Weight Babies in Public Hospitals, Eastern Ethiopia. Journal of Neonatal Biology. 2017; 6(3):264.

28. Bedaso A, Kebede E, Adamu T. Assessment of skin-to-skin contact (SSC) during the postpartum stay and its determinant factors among mothers at public health institutions in Ethiopia. BMC Research Notes. 2019; $12(1): 136$.

29. Nguah SB, Wobil PN, Obeng R, Yakubu A, Kerber KJ, Lawn JE, et al. Perception and practice of Kangaroo Mother Care after discharge from hospital in Kumasi, Ghana: A longitudinal study. BMC pregnancy and childbirth. 2011;11(1):99.

30. FMOH E. Newborn and Child Survival Strategy Document Brief Summary 2015/16-2019/20. Addis Ababa: Ethiopia FMOH. 2015.

31. Kassahun G, Efa A, Samuel H. Takers of Preterm and Low Birth Weight Infants in Health Care Settings, Hawassa, Southern Ethiopia, 2018.

32. Berhe M, Medhaniye AA, Kahsay G, Birhane E, Abay M. Essential neonatal care utilization and associated factors among mothers in public health facilities of Aksum Town, North Ethiopia, 2016. PloSone. 2017; $12(4$

\section{Tables}


Table 1:

The socio-demographic characteristics of respondents and children in determine the prevalence and association of health professional assisted KMC practice in Ethiopia, $(\mathrm{n}=2910)$.

\begin{tabular}{|c|c|c|c|}
\hline Variables & Categories & Frequency & Percent \\
\hline \multirow[t]{8}{*}{ Husband occupation } & Did not work & 398 & 13.7 \\
\hline & Professional/managerial & 355 & 12.2 \\
\hline & Clerical & 37 & 1.3 \\
\hline & Sales & 397 & 13.6 \\
\hline & Agricultural employee & 1040 & 35.7 \\
\hline & Service & 181 & 6.2 \\
\hline & Skilled manual & 356 & 12.2 \\
\hline & Unskilled manual & 146 & 5.0 \\
\hline \multirow[t]{8}{*}{ Maternal occupation } & Did not work & 1658 & 57.0 \\
\hline & Professional/managerial & 118 & 4.1 \\
\hline & Clerical & 38 & 1.3 \\
\hline & Sales & 446 & 15.3 \\
\hline & Agricultural employee & 424 & 14.6 \\
\hline & Service & 67 & 2.3 \\
\hline & Skilled manual & 112 & 3.8 \\
\hline & Unskilled manual & 47 & 1.6 \\
\hline \multirow[t]{2}{*}{ Head of household } & Male & 2350 & 80.8 \\
\hline & Female & 560 & 19.2 \\
\hline \multirow[t]{2}{*}{ Residence } & Urban & 1243 & 42.7 \\
\hline & Rural & 1667 & 57.3 \\
\hline \multirow[t]{5}{*}{ Maternal age } & $15-19$ & 143 & 4.9 \\
\hline & $20-24$ & 718 & 24.7 \\
\hline & $25-29$ & 894 & 30.7 \\
\hline & $30-34$ & 604 & 20.8 \\
\hline & $35-39$ & 401 & 13.8 \\
\hline
\end{tabular}




\begin{tabular}{|c|c|c|c|}
\hline & $40-44$ & 124 & 4.3 \\
\hline & $45-49$ & 26 & 0.9 \\
\hline \multirow[t]{4}{*}{ Maternal education } & No education & 1139 & 39.1 \\
\hline & Primary & 1036 & 35.6 \\
\hline & Secondary & 453 & 15.6 \\
\hline & Higher & 282 & 9.7 \\
\hline \multirow[t]{11}{*}{ Region } & Tigray & 484 & 16.6 \\
\hline & Afar & 111 & 3.8 \\
\hline & Amhara & 230 & 7.9 \\
\hline & Oromia & 267 & 9.2 \\
\hline & Somali & 237 & 8.1 \\
\hline & Benishangul & 213 & 7.3 \\
\hline & SNNPR & 322 & 11.1 \\
\hline & Gambela & 199 & 6.8 \\
\hline & Harari & 265 & 9.1 \\
\hline & Addis Adaba & 334 & 11.5 \\
\hline & Dire-dawa & 248 & 8.5 \\
\hline \multirow[t]{6}{*}{ Religion } & Orthodox & 1224 & 42.1 \\
\hline & Catholic & 18 & 0.6 \\
\hline & Protestant & 443 & 15.2 \\
\hline & Muslim & 1206 & 41.4 \\
\hline & Traditional & 6 & 0.2 \\
\hline & Other & 13 & 0.4 \\
\hline \multirow[t]{5}{*}{ Wealth index } & Poorest & 436 & 15.0 \\
\hline & Poorer & 393 & 13.5 \\
\hline & Middle & 362 & 12.4 \\
\hline & Richer & 397 & 13.6 \\
\hline & Richest & 1322 & 45.4 \\
\hline Readiness & Wanted then & 2315 & 79.6 \\
\hline
\end{tabular}




\begin{tabular}{|c|c|c|c|}
\hline & Wanted later & 452 & 15.5 \\
\hline & Wanted no more & 143 & 4.9 \\
\hline \multirow[t]{2}{*}{ Cigarette smoking } & No & 2886 & 99.2 \\
\hline & Yes & 24 & 0.8 \\
\hline \multirow[t]{2}{*}{ Chat chewing } & No & 2600 & 89.3 \\
\hline & Yes & 310 & 10.7 \\
\hline \multirow[t]{3}{*}{ Type of birth } & Single birth & 2814 & 96.7 \\
\hline & 1st of multiple & 51 & 1.8 \\
\hline & 2nd of multiple & 45 & 1.5 \\
\hline \multirow[t]{2}{*}{ Sex of the child } & Male & 1477 & 50.8 \\
\hline & Female & 1433 & 49.2 \\
\hline \multirow[t]{2}{*}{ Marital status } & Married & 2867 & 98.5 \\
\hline & Living with partner & 43 & 1.5 \\
\hline \multirow[t]{5}{*}{ Child size at birth } & Very large & 552 & 19.0 \\
\hline & Large & 446 & 15.3 \\
\hline & Average & 1277 & 43.9 \\
\hline & Very small & 227 & 7.8 \\
\hline & Small & 408 & 14.0 \\
\hline
\end{tabular}


Table2:

The association of health professionals assisted KMC practice and possible maternal, environmental, child, and households related factors in Ethiopia, $(n=2910)$

\begin{tabular}{|c|c|c|c|c|c|c|c|c|}
\hline \multirow[t]{2}{*}{ Variables } & \multirow[t]{2}{*}{ Categories } & \multicolumn{2}{|c|}{ HCPs assisted KMC } & \multicolumn{2}{|l|}{ OR } & \multicolumn{2}{|l|}{$\begin{array}{l}95 \% \\
\mathrm{Cl}\end{array}$} & \multirow{2}{*}{$\begin{array}{l}\text { P- } \\
\text { value }\end{array}$} \\
\hline & & No & Yes & COR & AOR & Lower & Upper & \\
\hline \multirow[t]{5}{*}{ Wealth index } & Poorest & $\begin{array}{l}216 \\
(19.6)\end{array}$ & $220(12.2)$ & $0.47 *$ & 0.60 & 0.43 & 0.81 & 0.001 \\
\hline & Poorer & $\begin{array}{l}189 \\
(17.2)\end{array}$ & 204(11.3) & $0.50 *$ & 0.62 & 0.46 & 0.86 & 0.001 \\
\hline & Medium & $\begin{array}{l}138 \\
(12.5)\end{array}$ & $224(12.4)$ & $0.76^{*}$ & 0.95 & 0.68 & 1.32 & 0.76 \\
\hline & Richer & $\begin{array}{l}139 \\
(12.6)\end{array}$ & $258(14.3)$ & 0.86 & 1.06 & 0.78 & 1.45 & 0.72 \\
\hline & Richest & $\begin{array}{l}420 \\
(38.1)\end{array}$ & $902(49.9)$ & 1 & 1 & -- & - & - \\
\hline \multirow[t]{2}{*}{ Residence } & Rural & $\begin{array}{l}712 \\
(64.6)\end{array}$ & $955(52.8)$ & $0.61^{*}$ & 0.77 & 0.59 & 1.00 & 0.05 \\
\hline & Urban & $\begin{array}{l}390 \\
(35.4)\end{array}$ & $853(47.2)$ & 1 & 1 & - & - & - \\
\hline \multirow[t]{2}{*}{ Head of } & Male & $\begin{array}{l}896 \\
(81.3)\end{array}$ & 1454(80.4) & 1 & 1 & - & - & - \\
\hline & Female & $\begin{array}{l}206 \\
(18.7)\end{array}$ & $354(19.6)$ & 1.06 & 1.03 & 0.84 & 1.25 & 0.80 \\
\hline \multirow[t]{2}{*}{$\begin{array}{l}\text { Khat } \\
\text { chewing }\end{array}$} & No & $\begin{array}{l}977 \\
(88.7)\end{array}$ & 1623(89.8) & 1 & 1 & - & - & - \\
\hline & Yes & $\begin{array}{l}125 \\
(11.3)\end{array}$ & $185(10.2)$ & 0.89 & 0.86 & 0.67 & 1.10 & 0.23 \\
\hline \multirow[t]{2}{*}{ Child sex } & Male & $\begin{array}{l}576 \\
(52.3)\end{array}$ & $901(49.8)$ & 1 & 1 & - & - & - \\
\hline & Female & $\begin{array}{l}526 \\
(47.7)\end{array}$ & $907(50.2)$ & 1.10 & 1.06 & 0.91 & 1.24 & 0.43 \\
\hline \multirow{2}{*}{$\begin{array}{l}\text { Maternal } \\
\text { education }\end{array}$} & $\begin{array}{l}\text { No } \\
\text { education }\end{array}$ & $\begin{array}{l}480 \\
(43.6)\end{array}$ & $659(36.4)$ & $0.70 *$ & 1.07 & 0.79 & 1.45 & 0.68 \\
\hline & Primary & $\begin{array}{l}375 \\
(34.0)\end{array}$ & $661(36.6)$ & 0.90 & 1.17 & 0.87 & 1.57 & 0.29 \\
\hline
\end{tabular}




\begin{tabular}{|lllllllll|}
\hline \multirow{5}{*}{ Child size at birth } & Secondary & $152(13.8)$ & $301(16.6)$ & 1.01 & 1.11 & 0.81 & 1.53 & 0.52 \\
\cline { 2 - 9 } & Higher & $95(8.6)$ & $187(10.3)$ & 1 & 1 & - & - & - \\
\cline { 2 - 9 } & Very large & $223(20.2)$ & $329(18.2)$ & 1 & 1 & - & - & - \\
\cline { 2 - 9 } & Large & $162(14.7)$ & $284(15.7)$ & 1.19 & 1.16 & 0.89 & 1.50 & 0.28 \\
\cline { 2 - 9 } & Average & $451(40.9)$ & $826(45.7)$ & $1.24^{\star}$ & 1.22 & 0.99 & 1.51 & 0.06 \\
\cline { 2 - 9 } & Small & $93(8.4)$ & $134(7.4)$ & 0.98 & 1.03 & 0.75 & 1.42 & 0.85 \\
\cline { 2 - 8 } & Very small & $173(15.7)$ & $235(13.0)$ & 0.92 & 0.96 & 0.74 & 1.25 & 0.76 \\
\hline & No & $991(89.9)$ & $1642(90.8)$ & 1 & 1 & - & - & - \\
\hline
\end{tabular}

*=p-value $<0.05$ 